\title{
Relationship between depression and risk of malnutrition among community-dwelling young-old and old-old elderly people.
}

\section{AUTHOR(S):}

Yoshimura, Kazuya; Yamada, Minoru; Kajiwara, Yuu; Nishiguchi, Shu; Aoyama, Tomoki

\section{CITATION:}

Yoshimura, Kazuya ... [et al]. Relationship between depression and risk of malnutrition among community-dwelling young-old and old-old elderly people.. Aging \& mental health 2012, 17(4): 456-460

\section{ISSUE DATE:}

2012-11

URL:

http://hdl.handle.net/2433/189833

\section{RIGHT:}

This is an Accepted Manuscript of an article published by Taylor \& Francis Group in "Aging and Mental Health" on 11/26/2012, available online at: http://www.tandfonline.com/10.1080/13607863.2012.743961; This is not the published version. Please cite only the published version:; この論文は出版社版でありません。引用の際には出版社版をご磪認ご 利用ください。 
1 Relationship between depression and risk of malnutrition among

2

3

4

5

6

7

8

9 Graduate School of Medicine, Kyoto University, Kyoto, Japan.

\section{community-dwelling young-old and old-old elderly people}

\section{Authors} Graduate School of Medicine, Kyoto University, Kyoto, Japan.

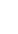
Graduate School of Medicine, Kyoto University, Kyoto, Japan. Graduate School of Medicine, Kyoto University, Kyoto, Japan. Graduate School of Medicine, Kyoto University, Kyoto, Japan.

Kazuya Yoshimura, Department of Physical Therapy, Human Health Sciences,

Minoru Yamada, Department of Physical Therapy, Human Health Sciences,

Yuu Kajiwara, Department of Physical Therapy, Human Health Sciences,

Shu Nishiguchi, Department of Physical Therapy, Human Health Sciences, 
22 Corresponding aurthor:

23 Kazuya Yoshimura

24 Department of Physical Therapy, Human Health Sciences, Graduate School of

25 Medicine, Kyoto University, Kyoto, Japan.

2653 Kawahara-cho, Shogoin, Sakyo-ku, Kyoto 606-8507, Japan

$27 \quad$ E-mail: yoshimura.kazuya.76w@st.kyoto-u.ac.jp

28 Phone: +81-75-751-3935

29 Fax: $+81-75-751-3909$

30

31 
32 Title

33 Relationship between depression and risk of malnutrition among

34 community-dwelling young-old and old-old elderly people

35

36 Journal

$37 \quad$ Aging \& Mental Health

38

$39 \quad$ Abstract

40 Objectives: The present study explores the association between nutritional

41 status and depression among healthy community-dwelling young-old (aged 65-

$42 \quad 74)$ and old-old elderly (aged 75 and older).

44 Method: A cross-sectional design was implemented. A total of 274

45 community-dwelling older individuals (142 young-old; 132 old-old) were

46 assessed using the Geriatric Depression Scale (GDS), Short-Form

47 Mini-Nutritional Assessment (MNA-SF), and Life-Space Assessment (LSA).

48 Logistic regression analysis was used to determine if depression was

49 independently associated with risk of malnutrition, stratified by age (young-old vs.

50 old-old). 
52 Results: In the logistic regression model for young-old, being at risk of

53 malnutrition (MNA-SF $\leqq 11$ ) was strongly associated with depression (GDS $\geqq$

545 ) (likelihood ratio $=6.26 ; 95 \%$ confidence interval $[\mathrm{CI}]: 1.91-20.49$ ). In contrast,

55 in the old-old group, the model was not statistically significant.

56

57 Conclusion: Depression and nutritional status were strongly correlated in

58 young-old but not in old-old community-dwelling elderly. This study reveals that

59 not only the factors correlated with but also the symptoms of depression may

60 vary among different age stratifications of the elderly.

61

62 Keywords: Depression, Nutritional Status, Young-old

63 


\section{Relationship between depression and risk of malnutrition among} community-dwelling young-old and old-old elderly people

Introduction

In an aging population, depression is a serious public health issue due to its societal burden and association with various factors. The total cost of depression in Japan in 2005 was estimated to be 2.0 trillion yen (USD 1 = JPY 78: October 2012) (Sado et al., 2011), which includes all direct, morbidity, and mortality costs. Further, studies in a variety of settings have shown that depression is strongly associated with low function and poor quality of life, increase in the use of health services, late-life suicide tendency, and excess mortality (Callahan, Hui, Nienaber, Musick, \& Tierney, 1994; Cuijpers \& Smit, 2002; Geerlings, Beekman, Deeg, Twisk, \& Van Tilburg, 2002; Koenig, Shelp, Goli, Cohen, \& Blazer, 1989; Nyunt, Lim, Yap, \& Ng, 2012; Turvey et al., 2002; Van der Weele, Gussekloo, De Waal, De Craen, \& Van der Mast, 2009; Wada et al., 2005). A systematic review of 34 community-based studies reported that the prevalence of depression in the elderly is as high as 35\% (Beekman, Copeland, \& Prince, 1999; Woo et al., 1994). In terms of the type of depression, major depression is relatively rare and minor depression more common (Beekman, Copeland, \& Prince, 1999). In 
84 addition, clinicians often fail to diagnose and treat depression in the elderly, and

85 elderly individuals are reluctant to report depressive symptoms (Georgotas,

86 Cooper, Kim, \& Hapworth, 1983; Lyness et al., 1995; Webber et al., 2005).

87 Therefore, depression in the elderly has often been unrecognized, and it is 88 important to clarify the components of depression to improve the sensitivity of 89 screening methods.

90

Many variables, including gender, marital status, cognitive status, activities of daily living and independent activities of daily living limitations, and social engagement, are associated with increased depression (Anstey, Von Sanden, Sargent-Cox, \& Luszcz, 2007; Glass, Mendes De Leon, Bassuk, \& Berkman, 2006). Meanwhile, weight loss and loss of appetite are the main factors that mediate the relationship between depression and nutritional status (Rubenstein, Harker, Salvà, Guigoz, \& Vellas, 2001). Recently, multiple studies have indicated an association between depression and nutritional status in various settings such as outpatient clinics and institutions and in the community (Cabrera, Mesas, Garcia, \& Andrade, 2007; Kaburagi et al., 2011; Smoliner et al., 2009; Wilson,

101 Vaswani, Liu, Morley, \& Miller, 1998). In these settings, depression is an 102 independent predictor of nutritional health and a major cause of weight loss 103 (Chen, Chang, Chyun, \& McCorkle, 2005; Morley \& Kraenzle, 1994; Thompson 
104 \& Morris, 1991). Conversely, better diet quality is beneficial for preventing and

105 improving depressive symptoms (Akbaraly et al., 2009; Lin \& Su, 2007). The

106 relationship between depression and nutritional status is interactive and further

107 investigation is still needed. In this regard, the aging society needs to be

108 considered. The word 'elderly' is very broad, encompassing all individuals aged

109 older than 60 or 65 years. Age may alter the relationship among the various

110 variables associated with depression. For example, the young-old (age 65-74

111 years) and old-old (age 75 years and above) have different predispositions

112 regarding various aspects of both depression and nutritional status (Kaburagi et

113 al., 2011; Kondo, Kazama, Suzuki, \& Yamagata, 2008). Older elderly are more

114 likely to experience frailty, physical illness, bereavement, and loneliness, which

115 are risk factors contributing to depression (Bruce, 2002; Blazer, 2002).

116 Investigating age-group differences may help in clarifying the correlation

117 between depression and nutritional status and in developing precise, 118 age-stratified interventions.

120 The purpose of the present study was to analyse the association between

121 depression and nutritional status in different age groups of

122 non-functionally-impaired, community-dwelling elderly. 
125 Methods

126 [Participants]

127 Study participants were recruited through advertisements in the local press and

128 at local healthcare events from April 2011 to June 2012. A total of 274

129 community-dwelling older individuals volunteered in the study. The inclusion

130 criteria were an age of 65 years or older, living in the community, and being able

131 to walk independently with or without a cane. The exclusion criteria ensured that

132 none of the participants had any indications of the following health problems: (a)

133 symptomatic cardiovascular disease, (b) neurological and orthopaedic disorders,

134 (c) peripheral neuropathy of the lower extremities, and (d) severe arthritis.

136 This study was approved by the Ethical Review Board of Kyoto University

137 Graduate School of Medicine, Kyoto, Japan.

[Variables]

140 The following variables were collected using a questionnaire.

142 Depression was screened for by the 15-item Geriatric Depression Scale (GDS)

143 (Yesavage, 1988), a validated and reliable self-report scale that detects 
144 depression in elderly people. Scores range from 0 to 15 . We used a cut-off of $4 / 5$,

145 which is a recommended indicator of depression in Japanese populations

146 (Murata, Kondo, Hirai, Ichida, \& Ojima, 2008; Yamazaki, Nakano, Saito, \& 147 Yasumura, 2012)

149 Nutritional status was assessed with the Short-Form Mini-Nutritional 150 Assessment (MNA-SF) (Rubenstein et al., 2001). MNA-SF includes 6 items 151 dealing with loss of appetite, weight loss, mobility, stress or illness, dementia or 152 depression, and body mass index (BMI). Scores range from 0 to 14. A score of 15312 or above indicates satisfactory nutritional status, a score of 8 to 11 implies 154 risk of malnutrition, and a score less than 7 suggest malnourishment.

156 Life-space mobility was assessed by the Life-Space Assessment (LSA) (Baker, 157 Bodner, \& Allman, 2003), a questionnaire that measures the spatial extent of 158 individuals in a given month. The LSA takes into account the frequency of travel 159 to different life-space levels (bedroom, driveway, within neighbourhood, outside 160 neighbourhood but within town, and out of town), and whether personal or 161 technical assistance was required to get to those levels. The composite scores 162 range from 0 to 120 . 
164 [Statistical Analysis]

165 Statistical analysis was carried out with the software package SPSS 20.0 (SPSS

166 Inc., Chicago, IL). Relationships between MNA-SF items and depression were 167 evaluated with chi-square tests. Multivariate analysis was performed to examine 168 the association between depression and risk of malnutrition. Step-up logistic 169 regression analysis was used to determine if depression (GDS $\geq 5$ ) was 170 independently associated with risk of malnutrition (MNA-SF $\leq 11$ ). In Model I, all 171 of the participants were analysed. Model II contained only young-old participants, 172 and Model III contained only old-old participants. Demographic factors (age, 173 gender, and BMI) and LSA were adjusted in each model. An acceptable level of 174 statistical significance was considered to be a $p$ value of $<.05$.

177 Results

178 Participant characteristics are shown in Table 1. The mean age was 74.33 (SD 179 4.72) years, and 185 participants (67.5\%) were female. Classifying participants 180 by age, 142 were young-old (51.8\%) and 132 participants were old-old (48.2\%).

181 Fifty-nine participants (21.5\%) were depressed. Seventy-seven (28.1\%) were at 182 risk of malnutrition (including 1 participant determined to be malnourished), and 183 the others were well nourished. Old-old participants had a higher risk of 
184 malnutrition than young-old ones, but no significant differences were found for

185 depression. The nutritional characteristics of the participants are shown in Table

186 2. Among the young-old, there was a trend that depressed participants were

187 more likely to have a loss of appetite within the past 3 months than the

188 non-depressed participants, but this difference was not statistically significant (p

$189=.075)$. There was no trend toward significance in the old-old group $(p=.502)$.

191 In the logistic regression model for young-old (Model II), being at risk of

192 malnutrition (MNA-SF $\leq 11$ ) was strongly associated with depression (GDS $\geq 5$ )

193 (likelihood ratio $=6.74 ; 95 \%$ confidence interval $[\mathrm{Cl}]: 2.11-21.51$ ) independent

194 from the control variables, while this association was not found in Models I and 195 III (Table 3).

Discussion

The present study found a correlation between GDS and MNA-SF for young-old

200 individuals, but not for old-old individuals or for the two groups combined.

201 Multiple studies conclude that depression and malnutrition are related, but that

202 the influence of age on the variables differs. Previous studies reported that depression is an independent predictor of malnutrition or nutritional risk even 
204 after adjusting for social and educational factors in young-old elderly adults but

205 not old-old elderly adults (Cabrera et al., 2007; Callen and Wells, 2005).These

206 differences could arise because depressive symptoms in the elderly have

207 different clinical features along the age spectrum from young-old to old-old

208 (Mehta et al., 2008). For example, old-old elderly may suffer from a higher

209 prevalence of disability or medical illnesses (Chou \& Chi, 2005). Having a

210 chronic disease is a variable that independently influences depression

211 (Schoevers et al., 2000). The relationship between depression and malnutrition

212 needs to be further examined, with physical, mental, and social status taken into

213 consideration.

215 Various studies have reported a positive relationship between depression and

216 nutritional status, and they often associate depression with loss of appetite or

217 weight loss (Akbaraly et al., 2009; Davison \& Kaplan, 2012). However, the rates

218 of depressed participants in the present study with loss of appetite or weight loss

219 were $13.6 \%$ and $30.5 \%$ in the young-old and old-old, respectively, and were

220 relatively low. Only the relationship between depression and loss of appetite in

221 young-old elderly showed a trend toward significance, and other relationships

222 (between depression and weight loss in young-old and between depression and

223 loss of appetite or weight loss in old-old) did not. Callen and Wells (2005) 
224 reported that in old-old elderly, depression is not a predictor of weight loss or low

225 BMI when adjusting for social, physical, and economic factors, a finding which is

226 in agreement with our results. The relationship between depression and loss of

227 appetite may have been the principal reason behind the result obtained in the

228 present multivariate analysis, that is, the positive relationship between

229 depression and malnutrition.

231 Our study has several limitations. The cross-sectional design prevents us from

232 making causal inferences. We also did not assess socioeconomic and

233 educational status and social support; the possibility of these being confounding

234 factors cannot be denied. Despite these limitations, this study reveals that the

235 factors correlated with depression could vary among different age groups of

236 elderly and suggests that depression and nutritional status are correlated more

237 strongly in young-old than old-old elderly. Future studies should focus on

238 clarifying the causal relationship, consider the age of subjects and assess

239 nutritional status, social status, etc., for better understanding of depression.

241 Reference

242 Akbaraly, T.N., Brunner, E.J., Ferrie, J.E., Marmot, M.G., Kivimaki, M., \&

243 Singh-Manoux, A. (2009). Dietary pattern and depressive symptoms in middle 
244 age. British Journal of Psychiatry, 195, 408-413

246 Anstey, K.J., Von Sanden, C., Sargent-Cox, K., \& Luszcz, M.A. (2007).

247 Prevalence and risk factors for depression in a longitudinal, population-based

248 study including individuals in the community and residential care. American

249 Journal of Geriatric Psychiatry, 15, 497-505

250

251 Baker, P.S., Bodner, E.V., \& Allman, R.M. (2003). Measuring Life-Space Mobility

252 in Community-Dwelling Older Adults. Journal of the American Geriatrics Society,

$51,1610-1614$

Beekman, A.T.F., Copeland, J.R.M., \& Prince, M.J. (1999). Review of community prevalence of depression in later life. British Journal of Psychiatry, 174, 307-311

Bruce, M.L. (2002). Psychosocial risk factors for depressive disorders in late life.

Biological Psychiatry, 52, 175-184

260

261

Blazer, DG. (2002). Depression in Later Life. New York: Springer.

Cabrera, M.A.S., Mesas, A.E., Garcia, A.R.L., \& de Andrade, S.M. (2007). 
264 Malnutrition and Depression among Community-dwelling Elderly People. 265 Journal of the American Medical Directors Association, 8, 582-584

267 Callahan, C.M., Hui, S.L., Nienaber, N.A., Musick, B.S., \& Tierney, W.M. (1994).

268 Longitudinal study of depression and health services use among elderly primary 269 care patients. Journal of the American Geriatrics Society, 48, 833-838

271 Callen, B.L. \& Wells, T.J. (2005). Screening for nutritional risk in 272 community-dwelling old-old. Public Health Nursing, 22, 138-146

274 Chen, C.C.-H., Chang, C.-K., Chyun, D.A., \& McCorkle, R. (2005). Dynamics of 275 nutritional health in a community sample of American elders: A multidimensional 276 approach using Roy Adaptation Model. Advances in Nursing Science, 28, $277 \quad 376-389$

Chou, K.-L. \& Chi, I. (2007). Prevalence and correlates of depression in Chinese oldest-old. International Journal of Geriatric Psychiatry, 20, 41-50

282 Cuijpers, P. \& Smit, F. (2002). Excess mortality in depression: A meta-analysis of community studies. Journal of Affective Disorders, 72, 227-236. 
285 Davison, K.M. \& Kaplan, B.J. (2012). Food intake and blood cholesterol levels of 286 community-based adults with mood disorders. BMC Psychiatry. Retrieved from 287 http://dx.doi.org/ 10.1186/1471-244X-12-10

289 Geerlings, S.W., Beekman, A.T., Deeg, D.J., Twisk, J.W., \& Van Tilburg, W. 290 (2002). Duration and severity of depression predict mortality in older adults in the 291 community. Psychological Medicine, 32, 609-618.

293 Georgotas, A., Cooper, T., Kim, M., \& Hapworth, W. (1983). The treatment of 294 affective disorders in the elderly. Psychopharmacology Bulletin, 19, 226-237

296 Glass, T.A., Mendes De Leon, C.F., Bassuk, S.S., \& Berkman, L.F. (2006). Social engagement and depressive symptoms in late life: Longitudinal findings. Journal of Aging and Health, 18, 604-628

Kaburagi, T., Hirasawa, R., Yoshino, H., Odaka, Y., Satomi, M., Nakano, M., ..., 301 Sato, K. (2011). Nutritional status is strongly correlated with grip strength and 302 depression in community-living elderly Japanese. Public Health Nutrition, 14, 1893-1899 
305 Koenig, H.G., Shelp, F., Goli, V., Cohen, H.J., \& Blazer, D.G. (1989). Survival 306 and health care utilization in elderly medical inpatients with major depression.

307 Journal of the American Geriatrics Society, 37, 599-606.

309 Kondo, N., Kazama, M., Suzuki, K., \& Yamagata, Z. (2008). Impact of mental 310 health on daily living activities of Japanese elderly. Preventive Medicine, 46, $311 \quad 457-462$

313 Lin, P.-Y. \& Su, K.-P. (2007). A meta-analytic review of double-blind,

314 placebo-controlled trials of antidepressant efficacy of omega-3 fatty acids.

315 Journal of Clinical Psychiatry, 68, 1056-1061

Lyness, J.M., Cox, C., Curry, J., Conwell, Y., King, D.A., \& Caine, E.D. (1995).

318 Older age and the underreporting of depressive symptoms. Journal of the American Geriatrics Society, 43, 216-221

Mehta, M., Whyte, E., Lenze, E., Hardy, S., Roumani, Y., Subashan, ...,

322 Studenski, S. (2008). Depressive symptoms in late life: Associations with apathy, resilience and disability vary between young-old and old-old. International 
326 Morley, J.E. \& Kraenzle, D. (1994). Causes of weight loss in a community 327 nursing home. Journal of the American Geriatrics Society, 42, 583-585

Murata, C., Kondo, K., Hirai, H., Ichida, Y., \& Ojima, T. (2008). Association between depression and socio-economic status among community-dwelling elderly in Japan: The Aichi Gerontological Evaluation Study (AGES). Health and

Place, 14, 406-414

Nyunt, M.S., Lim, M.L., Yap, K.B., \& Ng, T.P. (2012). Changes in depressive symptoms and functional disability among community-dwelling depressive older adults. International Psychogeriatrics (Epub ahead of print). Retrieved from http://dx.doi.org/10.1017/S1041610212000890

Rubenstein, L.Z., Harker, J.O., Salvà, A., Guigoz, Y., \& Vellas, B. (2001). Screening for undernutrition in geriatric practice: Developing the Short-Form Mini-Nutritional Assessment (MNA-SF). Journals of Gerontology - Series A 
344 Sado, M., Yamauchi, K., Kawakami, N., Ono, Y., Furukawa, T.A., Tsuchiya, M., 345 ..., Kashima, H. (2011). Cost of depression among adults in Japan in 2005. 346 Psychiatry and Clinical Neurosciences, 65, 442-450.

348 Schoevers, R.A., Beekman, A.T.F., Deeg, D.J.H., Geerlings, M.I., Jonker, C., \& 349 Van Tilburg, W. (2000). Risk factors for depression in later life; results of a 350 prospective community based study (AMSTEL). Journal of Affective Disorders, $59,127-137$

Smoliner, C., Norman, K., Wagner, K.-H., Hartig, W., Lochs, H., \& Pirlich, M. (2009). Malnutrition and depression in the institutionalised elderly. Current Opinion in Clinical Nutrition and Metabolic Care, 11, 1-6

Thompson, M.P. \& Morris, L.K. (1991). Unexplained weight loss in the ambulatory elderly. Journal of the American Geriatrics Society, 39, 497-500 \& Wallace R. (2002). Risk factors for late-life suicide: A prospective, community-based study. American Journal of Geriatric Psychiatry, 10, 398-406. 
364 Van der Weele, G.M., Gussekloo, J., De Waal, M.W.M., De Craen, A.J.M., \& Van

365 der Mast, R.C. (2009). Co-occurrence of depression and anxiety in elderly 366 subjects aged 90 years and its relationship with functional status, quality of life 367 and mortality. International Journal of Geriatric Psychiatry, 24, 595-601

Wada, T., Ishine, M., Sakagami, T., Kita, T., Okumiya, K., Mizuno, K., ..., Matsubayashi, K. (2005). Depression, activities of daily living, and quality of life of community-dwelling elderly in three Asian countries: Indonesia, Vietnam, and Japan. Archives of Gerontology and Geriatrics, 41, 271-280.

Webber, A.P., Martin, J.L., Harker, J.O., Josephson, K.R., Rubenstein, L.Z., \& Alessi, C.A. (2005). Depression in older patients admitted for postacute nursing home rehabilitation. Journal of the American Geriatrics Society, 53, 1017-1022 Wilson, M.-M.G., Vaswani, S., Liu, D., Morley, J.E., \& Miller, D.K. (1998). Prevalence and causes of undernutrition in medical outpatients. American Journal of Medicine, $104,56-63$ 
384 Chinese population. Acta Psychiatrica Scandinavica, 89, 8-13

385

386 Yamazaki, S., Nakano, K., Saito, E., \& Yasumura, S. (2012). Prediction of 387 functional disability by depressive state among community-dwelling elderly in 388 Japan: A prospective cohort study. Geriatrics and Gerontology International. $389 \quad$ Article in Press.

390

391 Yesavage, J.A. (1988). Geriatric Depression Scale. Psychopharmacology 392 bulletin, 24, 709-711. 
Table 1. Participant characteristics according to age

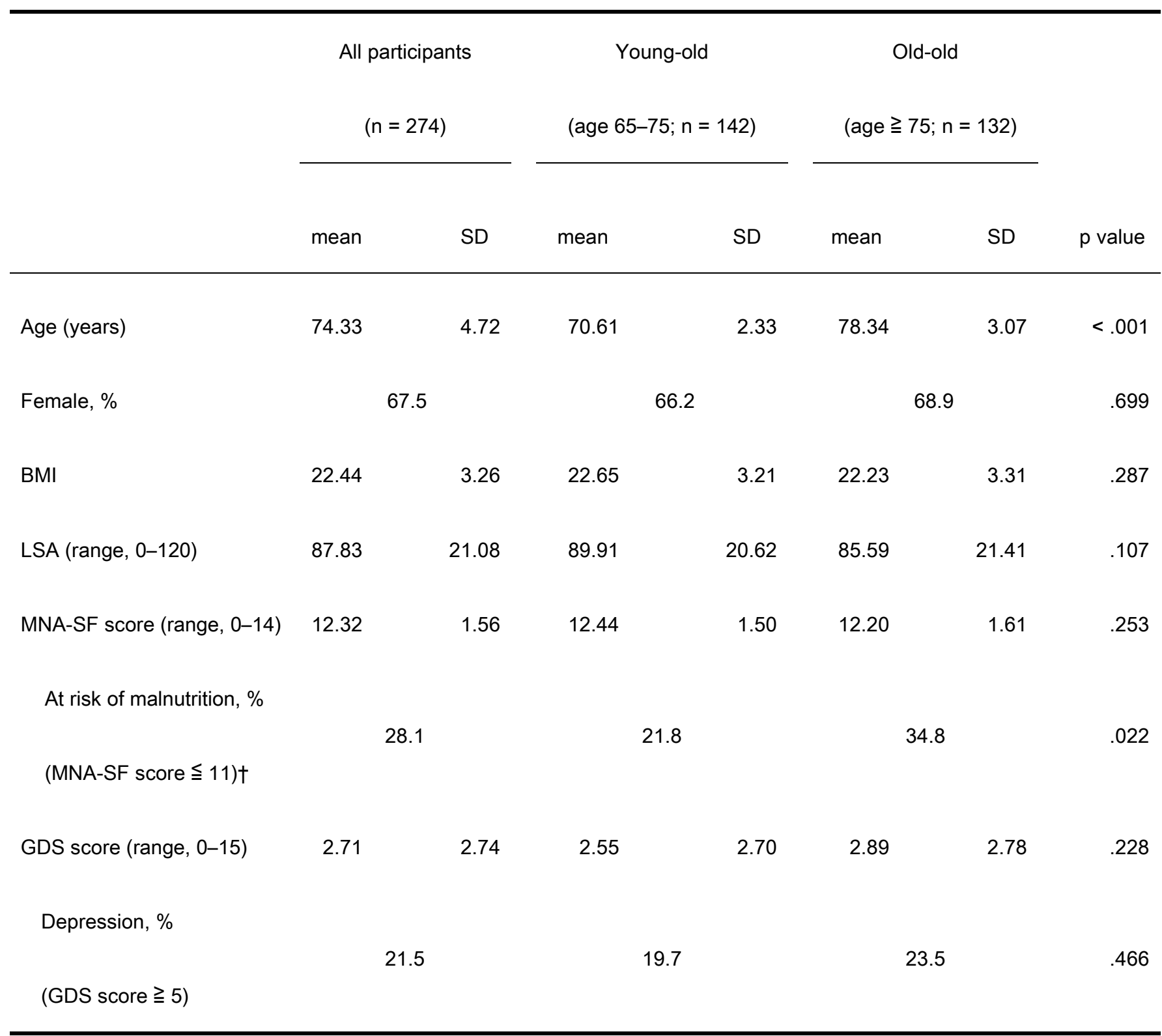

BMI: body mass index; LSA: Life-Space Assessment; MNA-SF: Short-Form Mini-Nutrition Assessment; GDS: Geriatric

Depression Scale

† Includes one participant classified as malnourished in the young-old group

$p$ values determined by Mann-Whitney $U$ test or chi-square test

395

396 
Table 2. Nutritional characteristics, measured by MNA-SF, of young-old and old-old participants with and without depression

\begin{tabular}{|c|c|c|c|c|c|c|c|c|c|}
\hline \multirow[b]{3}{*}{ MNA-SF items (ranking) $\dagger$} & \multicolumn{4}{|c|}{ With depression (GDS $\geqq 5$ ) } & \multicolumn{4}{|c|}{ Without depression $($ GDS $<5)$} & \multirow{3}{*}{$p$ value } \\
\hline & \multicolumn{4}{|c|}{ n (\%) } & \multicolumn{4}{|c|}{$n(\%)$} & \\
\hline & 0 & 1 & 2 & 3 & 0 & 1 & 2 & 3 & \\
\hline Young-old $(n=142)$ & & & & & & & & & \\
\hline Loss of appetite & $1(3.6)$ & $3(10.7)$ & $24(85.7)$ & - & $0(0)$ & $5(4.4)$ & $109(95.6)$ & - & .075 \\
\hline Weight loss & $0(0)$ & $3(10.7)$ & $6(21.4)$ & $19(67.9)$ & $0(0)$ & $6(5.3)$ & $13(11.4)$ & $95(83.3)$ & .108 \\
\hline Mobility & $0(0)$ & - & $28(100)$ & - & $0(0)$ & - & $114(100)$ & - & - \\
\hline Stress or acute illness & $6(21.4)$ & - & $22(78.6)$ & - & $7(6.1)$ & . & $107(93.9)$ & - & $.022^{*}$ \\
\hline Neuropsychological status & $2(7.1)$ & $1(3.6)$ & $25(89.3)$ & - & $0(0)$ & $0(0)$ & $114(100)$ & - & $.007^{* *}$ \\
\hline Body mass index & $4(14.3)$ & $6(21.4)$ & $7(25.0)$ & $11(39.3)$ & $11(9.6)$ & $16(14.0)$ & $45(39.5)$ & $42(36.8)$ & 1.000 \\
\hline
\end{tabular}

Old-old $(n=132)$ 


$\begin{array}{lccccccccc}\text { Loss of appetite } & 0(0) & 4(12.9) & 27(87.1) & - & 0(0) & 9(8.9) & 92(91.1) & - & .5097 \\ \text { Weight loss } & 0(0) & 3(9.7) & 6(19.4) & 22(71.0) & 3(3.0) & 6(5.9) & 12(11.9) & 80(79.2) & .3398 \\ \text { Mobility } & 0(0) & - & 31(100) & - & 0(0) & - & 101(100) & - & 399 \\ \text { Stress or acute illness } & 6(19.4) & - & 25(80.6) & - & 8(7.9) & - & 93(92.1) & .0700 \\ \text { Neuropsychological status } & 1(3.2) & 1(3.2) & 29(93.5) & - & 0(0) & 2(2.0) & 99(98.0) & - & .2801 \\ \text { Body mass index } & 3(9.7) & 8(25.8) & 6(19.4) & 14(40.6) & 17(16.8) & 21(20.8) & 22(21.8) & 41(40.6) & .681\end{array}$

MNA-SF: Short-Form Mini-Nutrition Assessment; GDS: Geriatric Depression Scale

$\dagger$ Higher scores indicate better function

Chi-square test: Loss of appetite and neuropsychological status, $0-1$ vs. 2; weight loss and body mass index, $0-2$ vs. 3; stress or acute

illness, 0 vs. 2

${ }^{*} \mathrm{p}<.05,{ }^{* *} \mathrm{p}<.01$ 
Table 3. Step-up logistic regression model of variables associated with depression (GDS $\geqq 5$ )

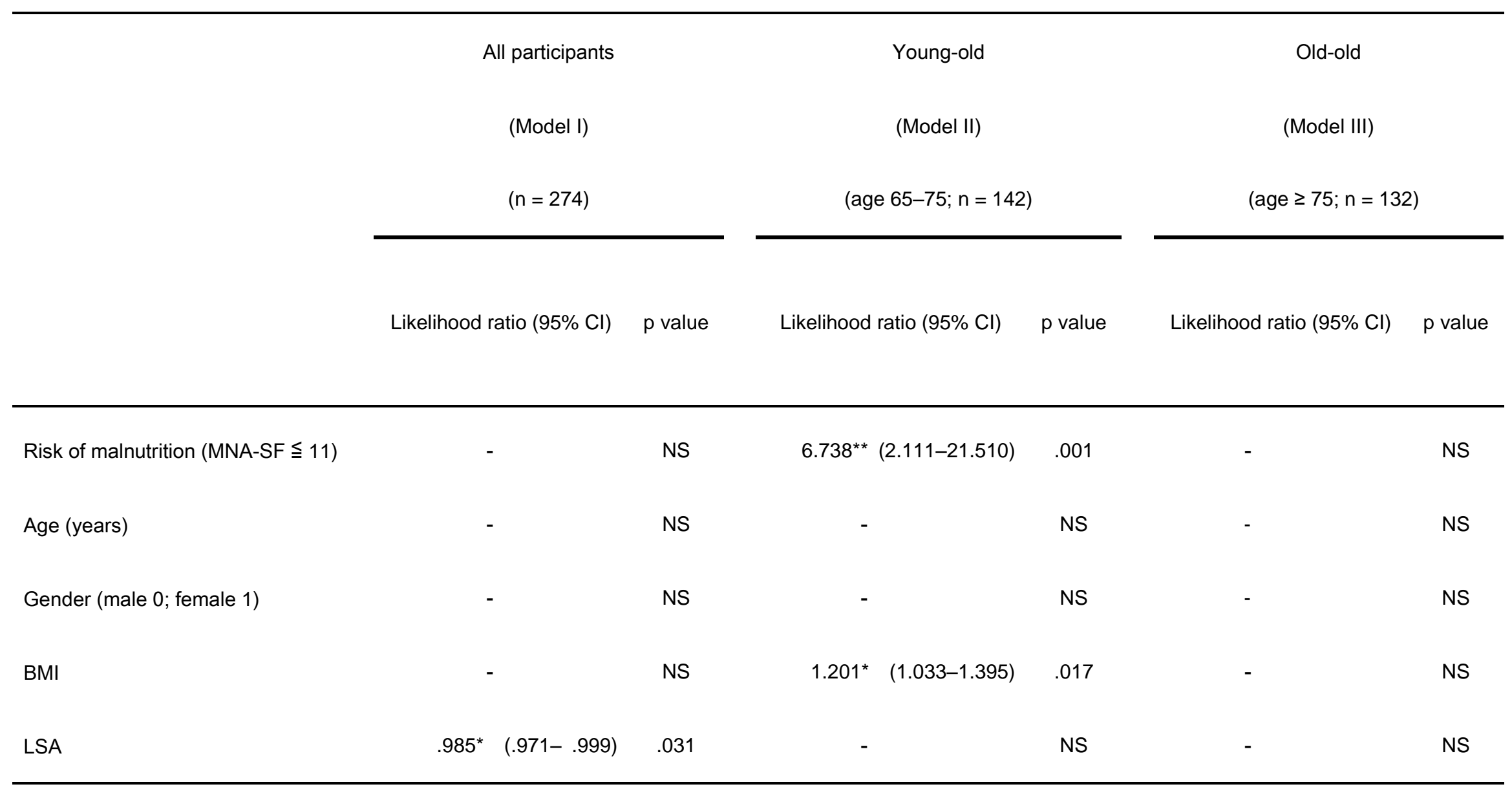

GDS: Geriatric Depression Scale; MNA-SF: Short-Form Mini-Nutrition Assessment; BMI Body Mass Index; LSA: Life-Space Assessment

NS: not selected 
${ }^{*} p<.05,{ }^{* *} p<.01$ 